\title{
Single Positive Core Prostate Cancer Has Less Aggressive Pathologic Features than Multiple Positive Core Prostate Cancer but Should It Still Be Considered an Indolent
} Tumor?

\author{
Ricardo Kupka, Marcos Francisco Dall'Oglio, Alexandre Crippa, José Pontes, \\ Aguinel José Bastian Júnior, Luís Felipe Piovesan, Willian Nahas, Miguel Srougi \\ Division of Uro-Oncology, University of São Paulo Medical School, São Paulo, SP, Brazil \\ Email: ricardokupka@hotmail.com, marcosdallogliouro@terra.com.br, drcrippa@uol.com.br, \\ docjpjr@uol.com.br, aguinel@gmail.com, Ifpiovesan@gmail.com, enfpesq2.urousp@gmail.com, \\ srougi@terra.com.br
}

Received 7 March 2014; revised 7 April 2014; accepted 14 April 2014

Copyright (C) 2014 by authors and Scientific Research Publishing Inc. This work is licensed under the Creative Commons Attribution International License (CC BY). http://creativecommons.org/licenses/by/4.0/

(c) (i) Open Access

\section{Abstract}

Introduction: A single positive core (SPC) in a prostate biopsy is usually associated with indolent prostate cancer (PCa), and is considered one active surveillance criteria. To determine if a SPC should qualify a patient for surveillance, we compared the pathological findings for SPC and multiple positive core in a matched population who underwent radical prostatectomy (RP). Material and Methods: We evaluated 373 SPC patients who underwent RP (Group 1) and 375 consecutive cases with multiple positive core (Group 2) who were matched according to age, prostate weight, PSA level and clinical stage. In addition to preoperative data and epidemiological characteristics, we compared the rates of positive surgical margins (PSMs), extraprostatic extension (EPE) and seminal vesicle invasion (SVI) according to the Gleason scores (GSs) of the biopsies. Results: Both groups were similar according age, PSA level, prostate weight and clinical stage. Group 1 had a lower PSM rate $(20.9 \%$ vs $37.6 \%, p<0.001)$, less EPE $(10 \%$ vs $26 \%, p<0.001)$ and SVI $(6 \%$ vs $13.3 \%, p=0.006)$. The PSM, EPE and SVI rates increased with increasing GS in both groups. In Group 1, a patient with a GS $\geq 8$ was 3.5 times more likely to have a PSM than a patient with a GS $\leq$ $6(p=0.03)$; with no difference in Group $2(p=0.162)$. There were no correlations between the EPE and SVI rates and the GS in Group 1 ( $p=0.273$ and $p=0.95$, respectively). However, in Group 2, we observed a higher rate of EPE among GS 7 than among GS $\leq 6,0 R=3.1(p<0.001)$. We also observed a higher rate of SVI among GS 7 than among GS $\leq 6$ in Group 2, $0 R=3.1(p=0.004)$. Conclusion: SPC PCa have reduced rates of PSM, EPE and SVI relative to multiple positive core. However, 
these pathologic findings were observed in $6.0 \%-20.9 \%$ of SPC, especially in undifferentiated tumors. These results led us to conclude that active treatment instead of active surveillance should be considered and must be evaluated individually for SPC patients, especially those with higher GSs.

\title{
Keywords
}

\author{
Prostate Cancer, Active Surveillance, Radical Prostatectomy, Prostate Biopsy
}

\section{Introduction}

Prostate cancer (PCa) is the most common malignancy in males and is the second leading cause of death among men in western countries, including Brazil. In the United States, 241,740 new cases and 28,170 deaths related to PCa are estimated for the year 2012 [1]. The widespread use of prostate-specific antigen (PSA)-based screening over the last few decades has resulted in stage migration at diagnosis, and currently, $3 / 4$ of patients have impalpable disease (cT1c), and less than 5\% have metastasis at diagnosis. In addition, it is not uncommon for tumors to be diagnosed by only one positive core, and these patients are commonly referred to as single positive core PCa patients. It has been postulated that single positive core PCa is usually associated with a lower stage, a low volume tumor and low-risk disease [2] [3].

It is believed that $20 \%$ to $30 \%$ of men with low-risk PCa in the US could be candidates for conservative approaches, including observational strategies or active surveillance [4]. One could theorize that single positive core PCa patients would be good candidates for these conservative approaches; however, there are few published studies on this subject.

The occurrence of extraprostatic extension (EPE), seminal vesicle invasion (SVI) or positive surgical margins (PSMs) for the surgical specimen is usually associated with an increased risk of biochemical recurrence and prostate cancer-specific death, and these factors preclude classifying tumors as indolent tumors [5]. To date, there has been no published study that has compared single positive core and multiple positive core PCa patients in a matched population and their relationship with the risk of PSM, EPE and SVI. Therefore, we decided to determine if single positive core PCa should be considered indolent PCa by analyzing the frequency of these events.

The aim of this study was to evaluate the pathologic outcomes after radical retropubic prostatectomy (RRP) in single and multiple positive core PCa patients in the PSA era.

\section{Material and Methods}

The study was an observational and retrospective analysis that was submitted to and approved by the ethics committee of HCFMUSP, under the number 12/9201. We retrospectively reviewed the patient records for all RRPs performed at São Paulo's State Cancer Institute (ICESP) between January 1, 2006, and January 30, 2013. We found 373 patients who underwent RRP for localized PCa and whose tumors were diagnosed by a single positive core biopsy (Group 1). As the control group (Group 2) we selected all consecutive PCa patients who underwent RRP from January 1, 2011 to July 30, 2012 (693 cases). Single positive core cases were excluded from this second group (129). The remaining 564 patients, who had $>1$ positive biopsy core, were matched with the patients in Group 1 according to age, prostate weight, PSA level and clinical stage to avoid selection bias. There were 375 patients with PCa diagnosed by multiple positive cores who were similar to the patients in Group 1 (373).

Men who had received prior hormonal treatment, radiotherapy or any other ablative treatment before RRP; patients for whom the data were incomplete or missing; and patients with pT0 tumors were excluded from the study (26 patients in Group 1 and 72 in Group 2).

We employed the Gleason grading system to analyze all biopsies and prostatectomy specimens. RRP specimens were submitted for histopathological examination by a group of experienced uropathologists at our institution. The 2002 TNM classification system was used to stage PCa. We evaluated the preoperative data, including epidemiological characteristics, biopsy data, clinical stage and PSA level, and the pathological data for the RRP 
specimens, including the frequencies of PSM, EPE and SVI. The groups were divided into three subgroups according to the Gleason score (GS) based on the biopsy: Gleason 6 (309 in Group 1 and 246 in Group 2), Gleason 7 (45 in Group 1 and 105 in Group 2) and Gleason 8 (19 in Group 1 and 24 in Group 2).

The pathological data for the single positive core patients (Group 1) were compared with the data for the patients with multiple positive cores (Group 2). Continuous variables such as age, PSA level, clinical stage, prostate weight and GS were analyzed by the Mann-Whitney test. The relationships between the biopsy and RRP specimens were analyzed by the chi-square test. Statistical significance in this study was set at $\mathrm{p}<0.05$. The analysis was performed using SPSS ver. 17.0.

\section{Results}

No significant differences were found in terms of the patient's age, PSA level, prostate weight and clinical stage between Group 1 and 2, thus confirming the similarity of the two groups (Table 1).

We found PSMs in 20.9\% of Group 1 patients and 37.6\% of Group 2 patients (Table 2), and this difference was statistically significant $(\mathrm{p}<0.001)$. In both groups, we observed that the rate of PSM increased with higher GS. In Group 1, a patient with a GS $\geq 8$ was 3.55 times more likely to have a PSM than a patient with a GS $\leq 6$

Table 1. Patients characteristics.

\begin{tabular}{cccc}
\hline & Group 1 (\%) & Group 2 (\%) & p \\
\hline No. of patients & 373 & 375 & - \\
Mean age (SD) & $65.5(6.4)$ & $64.4(5.9)$ & $0.083^{\mathrm{a}}$ \\
Mean ng/ml PSA (SD) & $9.76(7.1)$ & $10.73(7.9)$ & $0.128^{\mathrm{a}}$ \\
Mean weight g prostate (SD) & $55.7(26.7)$ & $51.4(22.4)$ & $0.102^{\mathrm{a}}$ \\
Clinical Stage & & & \\
cT1 & $278(74.7)$ & $251(66.8)$ & \\
cT2 & $90(24.1)$ & $119(31.6)$ & $0.153^{\mathrm{b}}$ \\
\hline
\end{tabular}

SD: Standard deviation, PSA: prostate specific antigen, Group 1: positive single core, Group 2: multiple positive core, ${ }^{a}$ Mann-Whitney test, ' chi-square test.

Table 2. Positive Surgical Margins according to the GS.

\begin{tabular}{cccc}
\hline & \multicolumn{3}{c}{ Positive Surgical Margins } \\
\hline Group 1 $1 \%)$ & No n (\%) & Total n (\%) \\
GS $\leq 6$ & $60(19.4)$ & $249(80.6)$ & $309(100)$ \\
GS 7 & $9(20.0)$ & $36(80.0)$ & $45(100)$ \\
GS $\geq 8$ & $9(47.3)$ & $10(52.7)$ & $19(100)$ \\
Total n (\%) & $78(20.9)$ & $295(79.1)$ & $373(100)$ \\
Group 2 & & & $246(100)$ \\
GS $\leq 6$ & $84(34.1)$ & $162(65.9)$ & $105(100)$ \\
GS 7 & $43(41.0)$ & $62(59.0)$ & $24(100)$ \\
GS $\geq 8$ & $13(54.1)$ & $11(45.8)$ & $375(100)$ \\
\hline Total n (\%) & $141(37.6)$ & $234(62.4)$ & \\
\hline
\end{tabular}

GS: Gleason Score. 
(95\% CI: 1.13 - 11.16 com $\mathrm{p}=0.030)$. There was no difference between GS 7 patients and GS $\geq 8$ patients $(\mathrm{p}=$ $0.137)$. We found no significant differences in Group 2 ( $p=0.162)$.

We found that $9.9 \%$ of Group 1 patients and $26.1 \%$ of Group 2 patients had EPE ( $<<0.001)$, as shown in Table 3. The rate of EPE increased with increasing GS in both groups; however, this relationship did not reach significance in Group $1(p=0.273)$. In Group 2, a significantly lower rate of EPE was observed for GS $\leq 6$ patients than for GS 7 and $\geq 8$ patients ( $p<0.001$ and $p=0.012$, respectively). GS 7 and GS $\geq 8$ patients hade, respectively, a 3.10-fold (IC: $1.66-5.79$ com p < 0.001) and a 4.65-fold (IC: $1.61-13.42, \mathrm{p}=0.004$ ) greater chance of having EPE than GS $\leq 6$ patients.

Table 4 demonstrates that SVI was found in 5.9\% and 13.3\% of Group 1 and Group 2 patients, respectively $(p=0.006)$. The rate of SVI was not related to the GS in Group $1(p=0.951)$. However, in Group 2, we observed that SVI was less common in GS $\leq 6$ patients than in GS 7 patients $(p=0.009)$. GS 7 patients were 3.17 times more likely to have SVI than GS $\leq 6$ patients (IC: $1.45-6.93 \mathrm{com} \mathrm{p}=0.004$ ). There was no correlation when $\mathrm{GS} \geq 8$ patients $(\mathrm{p}=0.180)$ were compared with the other patients.

Table 3. Extraprostatic Extension according to the GS.

\begin{tabular}{cccc}
\hline & \multicolumn{3}{c}{ Extraprostatic Extension } \\
\hline Group 1 & No n (\%) & Total n (\%) \\
GS $\leq 6$ & $28(9.1)$ & $281(90.9)$ & $309(100)$ \\
GS 7 & $4(8.9)$ & $41(91.1)$ & $45(100)$ \\
GS $\geq 8$ & $4(21.1)$ & $15(78.9)$ & $19(100)$ \\
Total n (\%) & $37(9.9)$ & $336(90.1)$ & $373(100)$ \\
Group 2 & & & \\
GS $\leq 6$ & $44(17.9)$ & $202(82.1)$ & $105(100)$ \\
GS 7 & $42(40)$ & $63(60)$ & $24(100)$ \\
GS $\geq 8$ & $12(50)$ & $12(50)$ & $375(100)$ \\
Total n (\%) & $98(26.1)$ & $277(73.9)$ & \\
\hline
\end{tabular}

GS: Gleason Score.

Table 4. Seminal Vesicle invasion according to the GS.

\begin{tabular}{cccc}
\hline & \multicolumn{3}{c}{ Seminal Vesicle Invasion } \\
\hline Group 1 & No n (\%) & Total n (\%) \\
GS $\leq 6$ & $18(5.8)$ & $291(94.2)$ & $309(100)$ \\
GS 7 & $3(6.7)$ & $42(93.3)$ & $45(100)$ \\
GS $\geq 8$ & $1(5.3)$ & $18(94.7)$ & $19(100)$ \\
Total n (\%) & $22(5.9)$ & $351(94.1)$ & $373(100)$ \\
Group 2 & & & \\
GS $\leq 6$ & $21(8.5)$ & $225(91.5)$ & $105(100)$ \\
GS 7 & $24(22.9)$ & $81(77.1)$ & $24(100)$ \\
GS $\geq 8$ & $4(16.7)$ & $20(83.3)$ & $375(100)$ \\
Total n (\%) & $50(13.3)$ & $325(86.7)$ & \\
\hline
\end{tabular}

GS: Gleason Score. 


\section{Discussion}

Thisis the first study in the literature to compare the pathologic findings of single positive core and multiple positive core PCa patients matched according to age, PSA, prostate weight and clinical stage. We observed that the single positive core group had better results for the PSM, EPE and SVI rates than the multiple positive core patients; however, these findings remained significant in Group 1, disqualifying them for active surveillance.

Although the clinical implications of single positive core PCa has not been clearly determined, the incidence of single positive core PCa appears to be increasing in the PSA screening era [6]. The use of PSA screening over the last several years has resulted in stage migration at PCa diagnosis. Active surveillance with delayed intervention appears to be a viable option for selected men with low-risk and low-volume PCa [7]-[9]. Many of these patients are diagnosed based on only a single positive core in the biopsy. Given that a single positive core PCa is likely an incipient tumor with a low volume, it is expected that these types of tumors are curable [10]. However, it has been shown that the presence of a small number of positive cores in the biopsy does not always correlate with a small PCa in the pathologic specimen [11].

Previous studies have shown that even patients with single positive cores have different prognoses according to the Gleason score [7]. Chaux et al. evaluated a single positive core population and reported that GS 8 PCa is associated with a higher likelihood of EPE, SVI and PSM than GS $\leq 7$ PCa. Patient selection for active surveillance is very important, and the main problem is that the decision is based on prostate biopsy findings, which are frequently incorrect. GS undergrading in particular is common [10] [12]. The main challenge is to identify those patients who are unlikely to experience significant progression while offering radical therapy to those who are at risk.

In our study, both groups had higher rates of PSM, SVI and EPE with increasing GSs. In Group 2, we found a significantly higher frequency of these events than in Group 1. These findings highlight the impact that GS has on PCa prognosis and underscores the necessity of proper grading for the accurate estimation of the likelihood of EPE, SVI and PSM, especially in single positive core patients [7].

Many studies have focused on single positive core PCa as a potential variable to identify insignificant PCa, and researchers have tried to determine whether it is possible to identify ideal candidates for conservative therapy [7] [10]. Therefore, the pathologic evaluation of this group of patients is of paramount importance. One strong point of our study is that we compared the pathologic outcomes of matched populations of single and multiple positive core patients.

The presence of a PSM after RRP is considered a poor prognostic factor [13] [14], but the impact of a PSM on clinical endpoints is a topic of ongoing debate [15]. Mauermann found that 34.5\% of pT2-T4 patients had PSMs. In our study, 20.9\% of the single positive core group and 37.6\% the multiple positive core group had PSMs ( $<$ < 0.001). Taverna et al. reported a PSM rate of 29.1\% among 134 patients with microfocus prostate adenocarcinomas [16]. In another study, the biopsy GS was reported to be higher for patients with PSMs than for patients with negative surgical margins [17]. In addition, Özgür et al. also found that the incidence of PSM among 171 patients was significantly higher for patients with a GS $\geq 7(p<0.05)$ [13]. We observed that the rate of PSM increased with increasing GS in both groups; however, this relationship was statistically significant for only the single positive core patients, underscoring the notion that active surveillance is not a good option for this group. Evaluating the EPE rates, a recent study of patients eligible for active surveillance, including single positive core biopsy cases, that used highly selective criteria found that $12.5 \%$ of patients had EPE, and only $26 \%$ of tumors were classified as “insignificant” [17]. Pepe et al. analyzed 56 patients with single neoplastic microfoci and found EPE in 27.3\% [18]. In the literature, the EPE rate in the general PCa population varies from 21\%to 35\% [13] [19]. We found similar results, with an EPE rate of 10\% in the single positive core group and $26 \%$ in the multiple positive core group. The GS is an independent factor predicting EPE, and there are data describing the relationship between EPE and GS. Ozgur et al. reported a positive correlation between the EPE rate and the GS for GS 2-6 and GS $\geq 7$, but no difference was noted between groups with a GS of 7 and a GS $>7$ [13]. This finding was similar to ours, where the rate of EPE increased with increasing GS in both groups, although this tend was significant only for Group 2. There are at least two plausible explanations for our results: sampling errors for the biopsies and the fact that PCa is usually associated with multifocal lesions [6].

Eggener et al. found that SVI and a GS $\geq 8$ were the strongest factors associated with prostate cancer death [20]. The prevalence of SVI in low-volume tumors is $5.0 \%$, similar to the prevalence found in our study [21]. In our series, we found a significant increase in SVI with higher GS in Group 2 when comparing GS $\leq 6$ patients 
with GS 7 patients. We theorize that the small number of patients with SVI and higher GS in Group 1, $\mathrm{n}=3$, can explain the lack of significance in this group.

To complement the mentioned was published a study with 23 years of follow-up (695 patients) that compare watchful waiting or radical prostatectomy in patients with early prostate cancer. The primary end points were death from any cause, death from prostate cancer and the risk of metastases. The number needed to treat to prevent one death was 8 . So extended follow-up confirmed a substantial reduction in mortality after radical prostatectomy [22].

We recognize that the retrospective nature and the small number of GS $\geq 8$ cases are the main limitations of this study; therefore, confirmation using a larger series of single positive core PCa patients is necessary to validate our results. Because this analysis was retrospective, it was inherently subjected to selection bias. However, one of the advantages of this study, in addition to its originality and the use of a standard surgical technique, is the use of matched populations to decrease the selection bias.

\section{Conclusion}

We observed that single positive core PCa patients have lower rates of PSM, EPE and SVI than multiple positive core patients. However, PSM, EPE and SVI were observed in $6.0 \%-20.9 \%$ of single positive core patients, especially in those patients with undifferentiated tumors. These results led us to conclude that active treatment instead of active surveillance should be considered and must be evaluated individually for SPC, especially those with higher GSs.

\section{References}

[1] Siegel, R., Desantis, C., Virgo, K., Stein, K., Mariotto, A., Smith, T., et al. (2012) Cancer Treatment and Survivorship Statistics, 2012. CA: A Cancer Journal for Clinicians, 62, 220-241. http://dx.doi.org/10.3322/caac.21149

[2] Chun, F.K., Briganti, A., Gallina, A., Hutterer, G.C., Shariat, S.F., Antebie, E., et al. (2007) Prostate Specific Antigen Improves the Ability of Clinical Stage and Biopsy Gleason Sum to Predict the Pathologic Stage at Radical Prostatectomy in the New Millenium. European Urology, 52, 1067-1074. http://dx.doi.org/10.1016/j.eururo.2007.03.018

[3] Cooperberg, M.R., Broering, J.M., Litwin, M.S., Lubeck, D.P., Metha, S.S., Henning, J.M., et al. (2004) The Contemporary Management of Prostate Cancer in the United States: Lessons from the Cancer of the Prostate Strategic Urologic Research Endeavor (CapSURE), a National Disease Registry. Journal of Urology, 171, 1393-1401. http://dx.doi.org/10.1097/01.ju.0000107247.81471.06

[4] Mouraviev, V., Mayes, J.M. and Polascik, T.J. (2009) Pathologic Basis of Focal Therapy for Early-Stage Prostate Cancer. Nature Reviews Urology, 6, 205-215. http://dx.doi.org/10.1038/nrurol.2009.29

[5] Chan, S.M., Garcia, F.J., Chin, J.L., Moussa, M. and Gabril, M.Y. (2011) The Clinical Significance of In-Depth Pathological Assessment of Extraprostatic Extension and Margin Status in Radical Prostatectomies for Prostate Cancer. Prostate Cancer and Prostatic Diseases, 14, 307-312. http://dx.doi.org/10.1038/pcan.2011.15

[6] Ahn, H.J., Young, H.K., Jang, H.A., Kang, S.G., Kang, S.H., Park, H.S., et al. (2010) Single Positive Core Prostate Cancer in a 12-Core Transrectal Biopsy Scheme: Clinicopathological Implications Compared with Multifocal Counterpart. Korean Journal of Urology, 51, 671-676. http://dx.doi.org/10.4111/kju.2010.51.10.671

[7] Chaux, A., Fajardo, D.A., Roibon, N.G., Partin, A.W., Eisenberger, M., DeWeese, T.L., et al. (2012) High-Grade Prostatic Adenocarcinoma in a Single Biopsy Core Is Associated with Increased Extraprostatic Extension, Seminal Vesicle Invasion, and Positive Surgical Margin at Prostatectomy. Urology, 79, 863-868.

http://dx.doi.org/10.1016/j.urology.2011.10.012

[8] Klotz, L., Zhang, L., Lam, A., Nam, R., Mamedov, A. and Loblaw, A. (2010) Clinical Results of Long-Term Follow-Up of a Large, Active Survveilance Cohort with Localized Prostate Cancer. Journal of Clinical Oncology, 28, 126-131. http://dx.doi.org/10.1200/JCO.2009.24.2180

[9] Van den Bergh, R.C.N., Roemeling, S., Roobol, M.J., Aus, G., Hugosson, J., Rannikko, A.S., et al. (2009) Outcomes of Men with Screen-Detected Prostate Cancer Eligible for Active Surveillance Who Were Managed Expectantly. European Urology, 55, 1-8. http://dx.doi.org/10.1016/j.eururo.2008.09.007

[10] Boccon-Gibod, L.M., Dumonceau, O., Toublanc, M., Ravery, V. and Boccon-Gibod, L.A. (2005) Micro-Focal Prostate Cancer: A Comparison of Biopsy and radical Prostatectomy Specimen Features. European Urology, 48, 895-899. http://dx.doi.org/10.1016/j.eururo.2005.04.033

[11] Anast, J.W., Andriole, G.M., Bismar, T.A., Yan, Y. and Humphrey, P.A. (2004) Relating Biopsy and Clinical Variables to Radical Prostatectomy Findings: Can Insignificant and Advanced Prostate Cancer Be Predicted in a Screen- 
ing Population? Urology, 64, 544-550. http://dx.doi.org/10.1016/j.urology.2004.04.008

[12] Epstein, J.I., Feng, Z., Trock, B.J. and Pierorazio, P.M. (2012) Upgrading and Downgrading of Prostate Cancer from Biopsy to Radical Prostatectomy: Incidence and Predictive Factors Using the Modified Gleason Grading System and Factoring in Tertiary Grades. European Urology, 61, 1019-1024. http://dx.doi.org/10.1016/j.eururo.2012.01.050

[13] Özgür, A., Önol, F.F. and Türkeri, L.N. (2004) Important Preoperative Prognostic Factors for Extracapsular Extension, Seminal Vesicle Invasion and Lymph Node Involvement in Cases with Radical Retropubic Prostatectomy. International Urology and Nephrology, 36, 369-373. http://dx.doi.org/10.1007/s11255-004-0746-z

[14] Gao, X., Mohideen, N., Flanigan, R.C., Waters, B., Wojcik, E.M. and Leman, C.R. (2000) The Extent of Biopsy Involvement as an Independent Predictor of Extraprostatic Extension and Surgical Margin Status in Low Risk Prostate Cancer: Implications for Treatment Selection. Journal of Urology, 164, 1982-1986. http://dx.doi.org/10.1016/S0022-5347(05)66933-9

[15] Mauermann, J., Fradet, V., Lacombe, L., Dujardin, T., Tiguert, R., Tetu, B., et al. (2012) The Impact of Solitary and Multiple Positive Surgical Margins on Hard Clinical End Points in 1712 Adjuvant Treatment-Naive pT2-4 N0 Radical Prostatectomy Patients. European Urology, 10 August 2012 [Epub ahead of print].

[16] Taverna, G., Benecchi, L., Grizzi, F., Seveso, M., Giusti, G., Piccinelli, A., et al. (2012) Can a Gleason 6 or Less Microfocus of Prostate Cancer in One Biopsy and Prostate-Specific Antigen Level $<10 \mathrm{ng} / \mathrm{mL}$ Be Defined as the Archetype of Low-Risk Prostate Disease? Journal of Oncology, 2012, Article ID: 645146.

[17] Beauval, J.B., Ploussard, G., Soulié, M., Pfister, C., Van Agt, S., Vincendeau, S., et al. (2012) Pathologic Findings in Radical Prostatectomy Specimens from Patients Eligible for Active Surveillance with Highly Selective Criteria: A Multicenter Study. Urology, 80, 656-660. http://dx.doi.org/10.1016/j.urology.2012.04.051

[18] Pepe, P., Fraggetta, F., Galia, A., Candiano, G., Grasso, G. and Aragona, F. (2010) Is a Single Focus of Low-Grade Prostate Cancer Diagnosed on Saturation Biopsy Predictive of Clinically Insignificant Cancer? Urologia Internationalis, 84, 440-444. http://dx.doi.org/10.1159/000296293

[19] Dall’Óglio, M.F., Crippa, A.S., Paranhos, M., Nesrralah, L.J., Leite, K.R. and Souri, M. (2005) Pathological Extension of Prostate Cancer as Defined by Gleason Score on Biopsy. International Brazilian Journal of Urology, 31, 326-330. http://dx.doi.org/10.1590/S1677-55382005000400005

[20] Eggener, S.E., Scardino, P.T., Walsh, P.C., Han, M., Partin, A.W., Trock, B.J., et al. (2011) Predicting 15-Year Prostate Cancer Specific Mortality after Radical Prostatectomy. Journal of Urology, 185, 869-875. http://dx.doi.org/10.1016/j.juro.2010.10.057

[21] Green, I.F., Black, A.D., Anchala, P.R., Catelona, W.J., Dimov, N.D., Yang, X.J., et al. (2012) Trends in Prostatic Adenocarcinoma Tumor Volume by Visual Estimation in Prostatectomy Specimens. Pathology—Research and Practice, 17 August 2012 [Epub ahead of print]. http://dx.doi.org/10.1016/j.prp.2012.06.006

[22] Bill-Axelson, A., Holmberg, L., Garmo, H., Rider, J.R., Taari, K., Busch, C., et al. (2014) Radical Prostatectomy or Watchful Waiting in Early Prostate Cancer. The New England Journal of Medicine, 370, 932-942. http://dx.doi.org/10.1056/NEJMoa1311593 
Scientific Research Publishing (SCIRP) is one of the largest Open Access journal publishers. It is currently publishing more than 200 open access, online, peer-reviewed journals covering a wide range of academic disciplines. SCIRP serves the worldwide academic communities and contributes to the progress and application of science with its publication.

Other selected journals from SCIRP are listed as below. Submit your manuscript to us via either submit@scirp.org or Online Submission Portal.
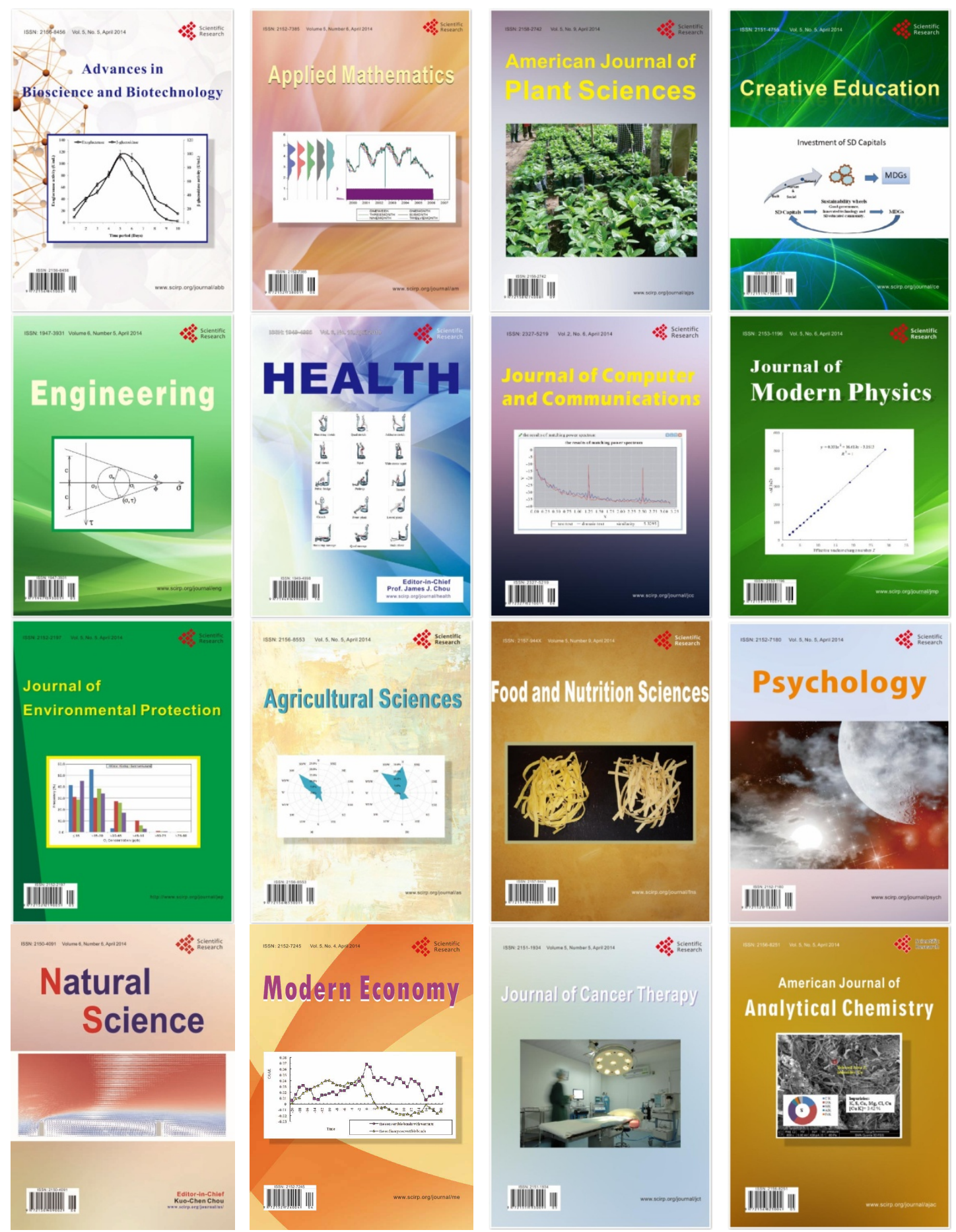